\title{
A METHODOLOGY FOR CONSTRUCTION RESEARCH PROGRAM DEVELOPMENT
}

\author{
Changyoon Kim, Hyoungkwan Kim, \\ Seung H. Han, Moon Kyum Kim \\ School of Civil and Environmental Engineering \\ Yonsei University, 134 Shinchon-dong, \\ Seodaemun-gu, Seoul, Korea 120-749 \\ \{Changyoonkim, hyoungkwan, shh6018, \\ applymkk\}@yonsei.ac.kr
}

\author{
Changwan Kim \\ Department of Architectural Engineering \\ Chung-Ang University \\ 221 Hueksuk-dong, Dongjak-gu, \\ Seoul, Korea 15-756 \\ changwan@cau.ac.kr
}

\begin{abstract}
Technology fusion is a new way of improving efficiency and effectiveness of construction technology research and development. Technology fusion indicates an interdisciplinary approach of combining different technology areas. To succeed in developing technology fusion-based construction research plans, two major approaches are adopted in this study: technology push investigation and market needs identification. Technology push investigation is to understand what types of technology are pushing the industry for improved business practices. Market needs are identified based on expert panel discussion, questionnaire-based survey, and committee reviews, in order to extract a range of technologies that are needed in the present construction industry. Through this process, 124 technology fusion-based research program candidates, which were first discovered from technology push and market demands investigation, were refined and reduced into 36 research programs. This paper presents the systematic methodology for developing the technology fusion-based research programs.
\end{abstract}

\section{KEYWORDS}

Construction Research, Technology Fusion, Technology Program Planning

\section{INTRODUCTION}

Technology fusion is one way of developing advanced construction technology. The technology fusion is defined as "a systematic interdisciplinary effort to destroy the walls between many science and engineering disciplines [1]." Combining stateof-the-art information technology, bio technology, nano technology, and environmental technology acts as a catalyst for enhancing construction research and development program. Through the interdisciplinary research and development, construction technology can be innovated.

Sometimes, research programs for technology development are not based on the needs of market. New technologies that were developed with significant investments often times end up not being used at all in the real business practices.
Therefore, attentions need to be paid to the current and future needs of the market and society. On the other hand, throughout the history of mankind, technologies have been the major factor that changes the society. New paradigms of business practices have always been the result of new technology developments. In summary, technology push and market demands both should be carefully considered to identify beneficial and promising research programs [2].

In this research, technology fusion-based research programs are developed through systematic approaches. To understand state-of-the-art technology trend, technology push factors are investigated. For ensuring that the identified program produces useful and beneficial results, market needs are studied. This process leads to a 
total of 124 technology fusion-based research program candidates. The candidates are refined and reduced into 36 research programs through survey and expert reviews. Finally, the top 10 research programs are presented after prioritizing them using various evaluation criteria.

\section{THE REVIEW OF THE METHODOLOGIES FOR TECHNOLOGY STRATEGY}

As previously mentioned, to succeed in developing technology fusion-based construction research plans, two major approaches are adopted in this study: 1) Technology push investigation, and 2) Market needs identification. This section provides the details of how these two approaches are used to identify the 124 candidate research programs.

\subsection{Technology Push Investigation}

Technology push investigation is to understand what types of technologies are pushing the industry for improved business practices. For this purpose, this study investigated academic papers, industry reports, and patents in the related fields.

The review of academic papers is an efficient method for identifying the trend of construction research and development. In this research, proceedings of ISARC (International Symposium on Automation and Robotics in Construction) and Journal of Automation in Construction from year 2000 to 2006 were reviewed to analyze the technology fusion based research trend. A total of 1,374 proceedings and journal papers were found in the area of technology fusion-based construction research and development. The 1,374 proceedings and journal papers were categorized into six areas, depending on where (in what phase of the project life cycle) the technology is used: 1) design optimization, 2) intelligent construction site, 3) procurement, 4) construction robot, 5) maintenance, and 6) the entire project lifecycle [3]. Also 46 keywords are extracted and used to produce patent maps. The database used is Aureka 9.0. United States, Japan, and European Union are the regions in which related patent information was searched. The patent search was conducted on the duration between January, 1991 and October, 2006. Patent maps were produced to make it easier to deduce the trend of research and development in the area of advanced construction technology [4].

Other interdisciplinary research programs were benchmarked, such as FIATECH (Fully Integrated and Automated TECHnology) capital project technology roadmap (CPTR) and CII (Construction Industry Institute) needs assessment. The FIATECH CPTR investigated 9 critical elements of advanced technologies across all phases of construction project lifecycle [5]. CII needs assessment showed the needs of owner, construction, and architecture/engineering companies to discover important research projects. CII, then, categorized the needs into construction, engineering, finance/risk, lifecycle, operation and workforce. Going through these processes, CII could reveal the tendency of the changes in construction industry, and suggest the plan for facing those challenges [6].

\subsection{Market Needs Identification}

Market needs are identified based on expert panel discussion, questionnaire-based survey, and committee reviews, in order to extract a range of technologies that are needed in the present and future construction industry. To figure out the technology needs of construction market, a 17member panel was organized. The experts in industry and academia formed the 17-member panel. They discussed the overall technology demand of construction industry, to deduce 18 market-driven technology needs.

A questionnaire-based survey was conducted, involving 340 experts, who work in academia, industry, and government supported research institutes. The questionnaire was originally distributed to a total of 2,472 people, obtaining the $14 \%$ of response rate. The survey questionnaire consists of three major parts. First, the survey asked how much impact new technologies would have on the future construction industry. Second, the market needs identified from the expert panel discussion were asked to be evaluated. Finally, each survey respondent was asked to suggest research programs considered to be the most important and urgent for dealing with the challenges of construction industry. The responses to the last question, along with the technology push investigation, resulted in the total of 124 new 
technology fusion-based research and development programs. The 124 programs were refined and reduced into 36 candidate programs through a committee review. The committee is composed of 27 members in academia, industry, and government organizations.

The 36 technology fusion-based research programs are also based on the vision and objectives of C4TF (Center for Technology Fusion). C4TF is an interdisciplinary research center, with the vision of a significant level of improvement in productivity, quality, and safety, through developing technology fusion-based research programs. The objectives of C4TF are: 1) fast and flawless design, 2) unmanned construction, 3) on-time construction, 4) extended life span of facility, 5) high-performance construction materials, and 6) multi-skilled highlevel human resources. There are 9 distinctive features of the developed 36 technology fusionbased research programs: 1) sustainability, 2) integration, 3) visualization, 4) automation, 5) optimization, 6) intelligence, 7) network, 8) high performance, and 9) high efficiency.

Table 1 Six Departments of Technology Programs

\begin{tabular}{|l|l|l|}
\hline No. & Department & $\begin{array}{l}\text { No. of } \\
\text { Programs }\end{array}$ \\
\hline 1 & Plan/Design & 5 \\
\hline 2 & Construction Robot & 7 \\
\hline 3 & Modularization & 5 \\
\hline 4 & Construction Management & 6 \\
\hline 5 & Maintenance Management & 7 \\
\hline 6 & New Materials & 6 \\
\hline Total & & 36 \\
\hline
\end{tabular}

The 36 technology fusion-based research programs are categorized into six departments: 1) plan/design, 2) construction robot, 3) modularization, 4) construction management, 5) maintenance management, and 6) new material. Each department has on average 6 research programs.
Each technology fusion-based program has RFP (Request For Proposal) which includes a technology description and a TRM (Technology Road Map). The RFP also includes the necessity and objective of the research program. Five or ten years of TRM is in the RFP, so each element technology has its own schedule as to when and what need to be done to achieve the technology fusion-based research program.

\subsection{Prioritizing Technology Fusion-based Research Program}

The Analytic Hierarchy Process (AHP) analysis was used for prioritizing the technology fusionbased research programs. The AHP analysis is a methodology of pairwise comparison for reflecting knowledge and experience of evaluators. In this research, 21 construction experts derived the criteria of evaluation and 298 experts evaluated the 36 candidate programs.

\section{THE ANALYSIS OF RESEARCH RESULT}

The evaluation criteria of AHP are: 1) possibility of creating new market, 2) current market needs, 3 ) policy, 4) goal achievement, and 5) potential market size. Possibility of creating new market is the degree of possibilities that the developed technologies are able to create new market or heavily change existing markets. Market needs is the expected demands of the developed technologies. Policy is a level of conformance with government policies for the welfare of the general public. Goal achievement is the possibility of accomplishing the technology development goal within the specified research period. Market size is the current market where the new technology can be sold at a good price. Each criterion was derived by 21 construction experts. The AHP result is indicated at Table 2 .

The highest criterion is the possibility of creating new market, and it obtains a 0.295 AHP score. Market needs and policy obtains 0.271 and 0.161 , respectively. Size of market obtains a 0.122 AHP score.

After deriving five criteria, 298 construction and other construction related experts out of 2,096 people $(14.2 \%)$ took part in the questionnaire- 
based survey for prioritizing the 36 candidate programs. Fig. 1 shows the organizations that the 298 survey respondents are affiliated with at the time of response. Experts from construction company accounts for biggest portion (64\%). Research institutes and academia account for 30\% and $21 \%$, respectively.

Table 2 Criteria of the AHP Analysis

\begin{tabular}{|l|l|l|}
\hline No. & Criteria & AHP score \\
\hline 1 & $\begin{array}{l}\text { Possibility of Creating } \\
\text { New Market }\end{array}$ & 0.295 \\
\hline 2 & Market Needs & 0.271 \\
\hline 3 & Policy & 0.161 \\
\hline 4 & Goal Achievement & 0.152 \\
\hline 5 & Size of Market & 0.122 \\
\hline Total & & 1.000 \\
\hline
\end{tabular}

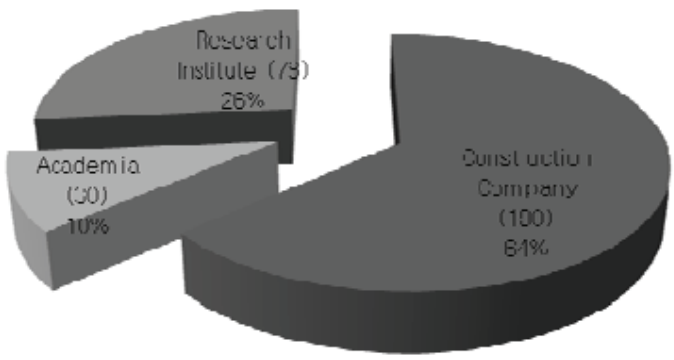

Figure 1 Affiliation of Respondents

Table 3 shows the top 10 research programs based on the AHP survey result, with the highest total score given to "Real-time Monitoring-based Construction Safety and Disaster Prevention/Management System” (0.245).

\section{CONCLUSIONS}

The systematic procedure has been introduced to identify promising technology fusion-based construction research programs, based on technology push investigation and market needs identification. The identified research programs were prioritized through the AHP analysis. To verify the technical feasibility of the research programs, pilot research are planned. In addition, an economic analysis is necessary to validate the developed research programs.

Table 3 Top 10 Technology Programs

\begin{tabular}{|c|c|c|}
\hline No. & Program Name & Total \\
\hline 1 & $\begin{array}{l}\text { Real-time Monitoring-based } \\
\text { Construction Safety and Disaster } \\
\text { Prevention/Management System } \\
\end{array}$ & 0.245 \\
\hline 2 & $\begin{array}{l}\text { Intelligence Lifeline Facility } \\
\text { Management System }\end{array}$ & 0.235 \\
\hline 3 & $\begin{array}{l}\text { Advanced Sensor-based Real-time } \\
\text { Project Management System }\end{array}$ & 0.234 \\
\hline 4 & $\begin{array}{l}\text { Integrated Asset Life-Cycle } \\
\text { Management Program }\end{array}$ & 0.228 \\
\hline 4 & $\begin{array}{l}\text { Developing Advanced High } \\
\text { Performance/ High Durability } \\
\text { Eco-friendly Construction } \\
\text { Finishing Material }\end{array}$ & 0.228 \\
\hline 6 & $\begin{array}{l}\text { Bridge Prefab and Automated } \\
\text { Construction for Rapid Urban } \\
\text { Construction }\end{array}$ & 0.226 \\
\hline 7 & $\begin{array}{l}\text { High-Performance Whole } \\
\text { Building Management System }\end{array}$ & 0.223 \\
\hline 8 & $\begin{array}{l}\text { Developing Advanced High } \\
\text { Performance Window Material for } \\
\text { Future Housing }\end{array}$ & 0.223 \\
\hline 9 & $\begin{array}{l}\text { Developing 3-D Geotechnical } \\
\text { Design System Using Advanced } \\
\text { Radar Technology and Integrated } \\
\text { Geotechnical Information } \\
\text { Database }\end{array}$ & 0.223 \\
\hline 10 & $\begin{array}{l}\text { Developing Thermal Energy } \\
\text { Adjustable Structural Window } \\
\text { System }\end{array}$ & 0.222 \\
\hline
\end{tabular}

\section{ACKNOWLEDGMENTS}

We gratefully acknowledge that this research is supported by Center for Technology Fusion in Construction (Grant No. "05 Technology Fusion A01") with the contribution of Korean Ministry of Construction and Transportation. 


\section{REFERENCES}

[1] Kim et al. (2006) Identifying the Demand for Innovative Future Construction Technology, Proceedings of the 23rd International Symposium on Automation and Robotics in Construction, Tokyo, Japan, October 3-5, 1114.

[2] Kim et al. (2007) Developing Technology Fusion-based Masterplan for Construction Research, Proceedings of COSEIK Annual Conference, Seoul, Korea, April 12-13, 57-61.

[3] Son et al. (2007) A Trend Analysis of Advanced Fusion Technology in the
Construction Industry, Proceedings of COSEIK Annual Conference, Seoul, Korea, April 12-13, 188-192.

[4] Cho et al. (2007) A Study on the Research Streams of Fusion R\&D for Construction Industry Using the Patent Analysis, Proceedings of COSEIK Annual Conference, Seoul, Korea, April 12-13, 193-196.

[5] www.fiatech.org

[6] www.construction-insitute.org 